\title{
Effect of Different Forms of Selenium on the Physiological Response and the Cadmium Uptake by Rice under Cadmium Stress
}

\author{
Haizhao $X u^{1}$, Jinpeng Yan $^{1}$, Yan Qin ${ }^{1}$, Jingmao $X u^{1}{ }^{1}$, M. J. I. Shohag ${ }^{2}{ }^{\oplus}$, Yanyan Wei ${ }^{1, *}$ and \\ Minghua $\mathrm{Gu}^{1, *}$ \\ 1 Cultivation Base of Guangxi Key Laboratory for Agro-Environment and Agro-Products Safety, National \\ Demonstration Center for Experimental Plant Science Education, College of Agriculture, Guangxi University, \\ Nanning 530004, China; xhz2020@st.gxu.edu.cn (H.X.); 1917392033@st.gxu.edu.cn (J.Y.); \\ qin_y@st.gxu.edu.cn (Y.Q.); xujingmao@st.gxu.edu.cn (J.X.) \\ 2 Department of Agriculture, Bangabandhu Sheikh Mujibur Rahman Science and Technology University, \\ Gopalganj 8100, Bangladesh; islam@zju.edu.cn \\ * Correspondence: yanyanwei@gxu.edu.cn (Y.W.); gumh@gxu.edu.cn (M.G.); Tel.: +86-186-0771-8450 (Y.W.); \\ +86-139-7716-8938 (M.G.)
}

Received: 1 September 2020; Accepted: 21 September 2020; Published: 24 September 2020

\begin{abstract}
Cadmium $(\mathrm{Cd})$ is a pollutant toxic to plants and a potential threat to human health. Selenium (Se), though not essential for plants, has beneficial effects on plants under abiotic stress. A hydroponic experiment was conducted to investigate the impact of different forms of Se (Nano-Se, selenite, selenate, and SeMet) on accumulation, subcellular distribution, and chemical forms of $\mathrm{Cd}$, as well as oxidative stress in rice seedlings. $\mathrm{Cd}\left(20 \mu \mathrm{mol} \cdot \mathrm{L}^{-1}\right)$ treatment significantly decreased biomass accumulation and chlorophyll content. The application of all Se forms, except selenate, mitigated the adverse effects of $\mathrm{Cd}$ on growth and chlorophyll content. The application of selenite, Nano-Se, and SeMet decreased root and shoot $\mathrm{Cd}$ concentrations as well as root-to-shoot $\mathrm{Cd}$ translocation in rice seedlings. Selenate application decreased shoot $\mathrm{Cd}$ concentration and root-to-shoot $\mathrm{Cd}$ translocation with no effect on root $\mathrm{Cd}$ concentration. Accordingly, Se increased the sequestration of $\mathrm{Cd}$ in the cell wall and vacuoles and decreased the active chemical form of $\mathrm{Cd}$ in rice seedlings. SeMet was the most effective supplement that decreased $\mathrm{Cd}$ concentration and enhanced Se concentration in the roots and shoots of rice seedlings. All forms of Se further enhanced catalase (CAT) and glutathione peroxidase (GSH-Px) activities and inhibited MDA accumulation. To conclude, Se influenced Cd accumulation and translocation in rice seedlings by altering the subcellular distribution, chemical forms, and antioxidant defense system under Cd stress. These effects were highly significant with SeMet treatment, probably due to better absorption and utilization by the plant.
\end{abstract}

Keywords: cadmium; selenium; rice

\section{Introduction}

Cadmium (Cd) is one of the most toxic heavy metals, and $\mathrm{Cd}$ soil pollution has become a serious global concern [1]. Plants grown under excess $\mathrm{Cd}$ show stunted growth and development due to the negative influence on physiological processes, such as photosynthesis, nutrient uptake, and water balance [2]. Moreover, a high concentration of $\mathrm{Cd}$ in plants causes oxidative damage via an increase in the formation of reactive oxygen species (ROS) and the effect on activities of antioxidant enzymes [3-5]. Rice (Oryza sativa L.) is one of the most important cereal crops globally, and about half of the world's population depends on it for food. Compared to other cereals, rice is considered an efficient $\mathrm{Cd}$ accumulator due to its ability to absorb $\mathrm{Cd}$ from the soil and further translocate into the grain [6]. It is 
a major dietary source of $\mathrm{Cd}[7,8]$. Cd concentration that exceeds the daily intake limit poses a risk to human health. Therefore, it is important to reduce the phytotoxic influence and absorption of $\mathrm{Cd}$ in rice to protect people from excessive $\mathrm{Cd}$ exposure and accumulation.

Selenium (Se) is a micronutrient essential for humans and animals. Although Se is not essential for higher plants, several studies have demonstrated the positive effects of Se on plant growth and abiotic stress tolerance at relatively low concentrations. In recent years, increased attention has been paid to the potential role of Se in alleviating heavy metal (including $\mathrm{Cd}$ ) toxicity in plants. Wan et al. [9] reported a decrease in root-to-shoot $\mathrm{Cd}$ translocation in rice seedlings supplemented with selenite [Se (IV)] and selenate [Se (VI)]. Se can combine with Cd and forms a stable Se-Cd complex in plants [10]. Ahmad et al. [11] found that Se (IV) application minimized the Cd oxidant effect and decreased lipid peroxidation and Cd uptake, transport, and distribution in Brassica juncea L. Additionally, Lin et al. [12] reported the ability of Se (IV) to reduce Cd availability. Se is also conducive to the recovery and reconstruction of the cell (cell membrane and chloroplast) structure under Cd stress [13]. Mozafariyan et al. [14] reported that Se (IV) addition reduced Cd accumulation and alleviated $\mathrm{Cd}$ toxicity in pepper via increased chlorophyll concentrations and total antioxidant activity. These studies together reveal the beneficial effects of Se, especially Se (IV) and Se (VI), in plants under Cd stress.

Different forms of Se exist in the environment. Se (IV) is the predominant form of Se in a well-drained mineral environment; however, Se (VI) is the main species in alkaline and well-oxidized conditions. Organic forms of Se also make up a major fraction of soil Se. Even low concentrations of organic Se in the soil are important as they are readily taken up by plant roots [15]. Schiavon et al. [16] found that the rate of selenomethionine (SeMet) uptake by wheat and canola was 20-fold more than that of Se (VI) or Se (IV). In recent years, nano-selenium, which is used in agricultural fields, medical therapy, as well as Se fertilization, has attracted attention [17]. Nano-sized elemental Se (selenium nanoparticles, SeNPs) formed via the reduction of Se oxyanions through biotic or abiotic pathways exist widely in the ambient [18]. Plants absorb and transform nano-selenium into inorganic Se compounds, such as Se (IV) and Se (VI), in the roots and shoots [19]. Se (IV) and Se (VI) effectively reduce Cd uptake at the whole-plant level; however, the mechanisms that alleviate $\mathrm{Cd}$ stress remain unaddressed. Besides, the species of Se involved in the effective mitigation of $\mathrm{Cd}$ phytotoxicity remain unknown.

In this study, we analyze the effects of four different forms of Se at varying concentrations on rice growth and $\mathrm{Cd}$ absorption and transport under $\mathrm{Cd}$ stress via a hydroponic experiment. This study addresses the effects of Se in alleviating Cd stress and the underlying mechanisms in rice seedlings.

\section{Materials and Methods}

\subsection{Hydroponic Culture of Rice and Sources of Se}

A hydroponic experiment was carried out at Guangxi University, Guangxi, China under the following conditions: $28 / 20{ }^{\circ} \mathrm{C}$ day/night temperatures, with $70 \%$ relative humidity and 240-350 $\mu \mathrm{mol} \cdot \mathrm{m}^{-2} \cdot \mathrm{s}^{-1}$ light. Rice seeds (Oryza sativa L. cv. Y Liangyou No. 7) were obtained from the seed market in Naning, Guangxi, China. The selenite and selenate were purchased from Sigma (ST Louis, MO, USA), and the selenomethionine was purchased from Yeyuan Bio-technology (Shanghai, China). Chemosynthesized nano-selenium was prepared following the method by Wu and $\mathrm{Ni}$ [20]. Nano-selenium synthesized via the reduction of sodium selenite $\left(\mathrm{Na}_{2} \mathrm{SeO}_{3}\right)$ using $\mathrm{NH}_{2} \mathrm{OH} \cdot \mathrm{HCl}$ and sodium alginate was used as the soft template. Nano-selenium particles used in this study were round or elliptic red nanospheres with a diameter of 50-100 $\mathrm{nm}$. The seeds were sterilized with $35 \%$ $(v / v)$ hydrogen peroxide $\left(\mathrm{H}_{2} \mathrm{O}_{2}\right)$ solution for $15 \mathrm{~min}$, washed three times with deionized water, placed in a plastic mesh, and soaked in $0.5 \mathrm{~mol} \cdot \mathrm{L}^{-1} \mathrm{CaSO}_{4}$ in a container covered with aluminum foil for 10 days. After germination, uniform rice seedlings were subsequently used for the pre-hydroponic experiment in plastic pots containing $2.5 \mathrm{~L}$ of nutrient solution (eight plants per pot). The composition of the nutrient was $\left(\mathrm{mmol} \cdot \mathrm{L}^{-1}\right): \mathrm{NH}_{4} \mathrm{NO}_{3} 1.45, \mathrm{NaH}_{2} \mathrm{PO}_{4} 0.32, \mathrm{~K}_{2} \mathrm{SO}_{4} 0.5, \mathrm{CaCI}_{2} 1.0 \mathrm{mmol} \cdot \mathrm{L}^{-1}, \mathrm{MgSO}_{4} \cdot 7 \mathrm{H}_{2} \mathrm{O}$ 
1.7, $\mathrm{MnCl}_{2} \cdot 4 \mathrm{H}_{2} \mathrm{O} 9.1 \times 10^{-3},\left(\mathrm{NH}_{4}\right)_{6} \mathrm{MoO}_{24} \cdot 4 \mathrm{H}_{2} \mathrm{O} 5.2 \times 10^{-4}, \mathrm{H}_{3} \mathrm{BO}_{3} 1.8 \times 10^{-2}, \mathrm{ZnSO}_{4} \cdot 7 \mathrm{H}_{2} \mathrm{O} 1.5 \times$ $10^{-4}, \mathrm{CuSO}_{4} \cdot 5 \mathrm{H}_{2} \mathrm{O} 1.6 \times 10^{-4}$, and $\mathrm{FeCl}_{2} \cdot 6 \mathrm{H}_{2} \mathrm{O} 3.6 \times 10^{-2}$. The solution was renewed every three days throughout the entire experiment.

Fifteen days later, the seedlings were exposed to different treatments containing $20 \mu \mathrm{mol} \cdot \mathrm{L}^{-1}$ $\mathrm{CdCl}_{2}$, with $1 \mu \mathrm{mol} \cdot \mathrm{L}^{-1}$ Se as either selenite $\left(\mathrm{Na}_{2} \mathrm{SeO}_{3}\right)$, selenate $\left(\mathrm{Na}_{2} \mathrm{SeO}_{4}\right)$, Nano-Se or SeMet, and the treatments were represented as Cd, Cd + Nano-Se, Cd + Se (IV), Cd + Se (VI), and Cd + SeMet, respectively. A control treatment (without $\mathrm{Cd}$ or Se) was also included. The experiment was laid in a completely randomized design with three replicates. After 25 days, the plants were harvested, divided into shoots and roots, and washed with deionized water. The fresh weight of rice roots and shoots was recorded. Half of the rice roots and shoots were dried and weighed. Another half of the rice roots and shoots were ground into a powder in liquid nitrogen and frozen at $-80^{\circ} \mathrm{C}$ until further use.

\subsection{Determination of Chlorophyll Content in Plant}

The chlorophyll content was assayed spectrophotometrically. Fresh leaves $(0.2 \mathrm{~g})$ were added to a tube containing $2 \mathrm{~mL}$ of $100 \%$ acetone. After shaking for $24 \mathrm{~h}$ at $4{ }^{\circ} \mathrm{C}$, the absorbance was read at $645 \mathrm{~nm}$ and $663 \mathrm{~nm}$ using a spectrophotometer to determine chlorophyll content [21].

\subsection{Determination of Se and Cd in Root and Shoot}

The root or shoot sample $(0.2 \mathrm{~g})$ and $6 \mathrm{~mL}$ of concentrated nitric acid were taken in a digestion tube, closed with the lid, and placed overnight in a fume cupboard. Subsequently, a microwave (CEM, MARS5, Charlotte, NC, USA) was used for digestion, followed by acid extraction with $6 \mathrm{~mL}$ of concentrated hydrochloric acid. The concentrations of $\mathrm{Cd}$ and Se were determined by inductively coupled plasma mass spectrometry (ICP-MS, NEXION 350X, PerkinElmer ${ }^{\mathrm{TM}}$ Life Science Incorporated, Waltham, MA, USA) [9].

\subsection{Determination of Subcellular Distribution of $\mathrm{Cd}$}

The subcellular components of $\mathrm{Cd}$ were determined by differential centrifugation [22]. The fresh root sample $(0.5 \mathrm{~g})$ was homogenized in $20 \mathrm{~mL}$ of a pre-cooled extracted solution containing $0.05 \mathrm{~mol} \cdot \mathrm{L}^{-1}$ Tris buffer ( $\mathrm{pH} 7.6), 1 \mathrm{mmol} \cdot \mathrm{L}^{-1}$ dithioerythritol, and $0.25 \mathrm{~mol} \cdot \mathrm{L}^{-1}$ sucrose. The homogenate was centrifuged for $10 \mathrm{~min}$ at $300 \mathrm{r} \cdot \mathrm{min}^{-1}$ in a refrigerated centrifuge and precipitated to obtain the cell wall. The supernatant was subsequently centrifuged for $15 \mathrm{~min}$ at $2000 \mathrm{r} \cdot \mathrm{min}^{-1}$ and precipitated to obtain the organelles (nucleus and chloroplast). The supernatant was further centrifuged for $20 \mathrm{~min}$ at $10,000 \mathrm{r} \cdot \mathrm{min}^{-1}$ and precipitated to obtain the cell membranes. The final supernatant is the soluble fraction of the cell that contains vacuoles, ribosomes, and nuclear proteins. All operations were performed at $4{ }^{\circ} \mathrm{C}$.

\subsection{Determination of Chemical Forms of $C d$}

Cadmium chemical forms were extracted and separated following the sequential extraction method [23]. The extraction agents (1) $80 \%$ ethanol (extraction of inorganic salts, mainly nitrates and chlorides, as well as amino acid salts); (2) deionized water $\left(\mathrm{H}_{2} \mathrm{O}\right.$, extraction of organic salts); (3) $1 \mathrm{~mol} \cdot \mathrm{L}^{-1}$ sodium chloride $(\mathrm{NaCl}$, extraction of pectin salt, which extracts the heavy metal in the binding state or adsorption state with protein); (4) $2 \%$ acetic acid (HAc, extraction of insoluble heavy metal phosphates); and (5) $0.6 \mathrm{~mol} \cdot \mathrm{L}^{-1}$ hydrochloric acid ( $\mathrm{HCl}$, extraction of oxalates) were used. The concentration of $\mathrm{Cd}$ obtained in each extraction step was measured using an inductively coupled plasma-mass spectrometer (ICP-MS, NEXION 350X, PerkinElmerTM Life Science Incorporated, Waltham, MA, USA) 
2.6. Determination of Malondialdehyde, Superoxide Dismutase, Peroxidase, Catalase, and Glutathione Peroxidase

To determine the antioxidant enzyme activity, fresh root $(0.2-0.5 \mathrm{~g})$ was rinsed; the root sample and PBS were taken in a centrifuge tube at a ratio of 1:4 (weight: volume; g: $\mathrm{mL}$ ). Approximately $20 \%$ of the tissue homogenate was ground with a tissue tamper $\left(10,000-15,000 \mathrm{r} \cdot \mathrm{min}^{-1}\right)$ and centrifuged at $4000 \mathrm{r} \cdot \mathrm{min}^{-1}$ at $4{ }^{\circ} \mathrm{C}$ for $10 \mathrm{~min}$. The resulting supernatant was collected to determine superoxide dismutase (SOD), catalase (CAT), peroxidase (POD), and glutathione peroxidase (GSH-Px) activities and malondialdehyde (MDA) content according to the method by Li et al. [24] using the assay kits (Jiancheng Bioengineering Institutes, Nanjing, China).

\subsection{Statistical Analyses}

All data were expressed as mean \pm standard deviation of three replicates. Statistical analysis software SPSS19.0 (International Business Machines Corporation, New York, NY, USA) was used to test the significance of the difference at $95 \%$ confidence interval. The data were analyzed and plotted using GraphPad Prism 7 (GraphPad Software Inc., San Diego, CA, USA).

\section{Results}

\subsection{Effects of Se Forms on Growth and Chlorophyll Content of Rice under Cd Stress}

Compared to the control, the root and shoot dry weights of rice seedlings treated with $\mathrm{Cd}$ were significantly reduced by $23 \%$ and $30 \%$, respectively (Table 1 ). However, when Cd-stressed plants were supplemented with SeMet, Se (IV), and Nano-Se, the root dry weight significantly increased by $118 \%$, $67 \%$, and $30 \%$, respectively, compared with Cd alone treatment. The shoot dry weight of rice seedlings treated with SeMet and Se (IV) significantly increased by $51 \%$ and $96 \%$, respectively, compared with the seedlings treated with Cd alone. Meanwhile, Se (VI) treatment significantly decreased the root dry weight of rice seedlings by $11 \%$.

Table 1. Effects of Se forms on the mass of roots or shoots and chlorophyll content in the presence of Cd. Data are expressed as mean values $\pm \mathrm{SD}(n=3)$. The different letters indicate statistically significant differences between the treatments at $p<0.05$.

\begin{tabular}{|c|c|c|c|}
\hline Treatments & $\begin{array}{l}\text { Root Mass } \\
\left(\mathrm{mg} \cdot \text { plant }^{-1}\right)\end{array}$ & $\begin{array}{l}\text { Shoot Mass } \\
\left(\mathrm{mg}^{\text {plant }}{ }^{-1}\right)\end{array}$ & $\begin{array}{l}\text { Chlorophyll Content } \\
\left(\mathrm{mg} \cdot \mathrm{g}^{-1}\right)\end{array}$ \\
\hline Control & $118.77 \pm 1.10^{c}$ & $687.50 \pm 15.00^{c}$ & $4.26 \pm 0.10^{a}$ \\
\hline $\mathrm{Cd}$ & $91.06 \pm 2.32^{d}$ & $484.00 \pm 8.72^{d}$ & $3.30 \pm 0.10^{c}$ \\
\hline $\mathrm{Cd}+$ Nano-Se & $118.29 \pm 1.21^{\mathrm{c}}$ & $465.83 \pm 21.26^{d}$ & $3.44 \pm 0.10^{c}$ \\
\hline $\mathrm{Cd}+\mathrm{Se}(\mathrm{VI})$ & $80.98 \pm 3.23^{\mathrm{e}}$ & $312.50 \pm 12.50^{\mathrm{e}}$ & $3.35 \pm 0.07^{c}$ \\
\hline $\mathrm{Cd}+\mathrm{Se}(\mathrm{IV})$ & $152.08 \pm 1.40^{b}$ & $948.89 \pm 20.09^{a}$ & $3.52 \pm 0.30^{c}$ \\
\hline $\mathrm{Cd}+$ SeMet & $198.77 \pm 1.52^{\mathrm{a}}$ & $731.11 \pm 8.39 b$ & $3.89 \pm 0.07^{b}$ \\
\hline
\end{tabular}

Chlorophyll content in rice leaves was significantly reduced by $29 \%$ under Cd stress, compared with the control treatment (Table 1). However, the chlorophyll content of $\mathrm{Cd}+$ SeMet treatment was significantly increased by $18 \%$, compared with $\mathrm{Cd}$ alone treatment. There was no significant $(p>0.05)$ difference in chlorophyll content among Cd + Nano-Se treatment, Cd + Se (IV) treatment, Cd + Se (VI) treatment, and $\mathrm{Cd}$ alone treatment. SeMet supplement was more effective in improving root and shoot dry weights of rice seedlings and chlorophyll content under Cd stress than other forms of Se.

\subsection{Effects of Se Forms on Cd Content in Rice Roots and Shoots and Transport Factor}

$\mathrm{Cd}$ concentration in rice roots and shoots were affected by different levels and forms of Se under Cd stress (Figure 1). Cd + Nano-Se treatment, $\mathrm{Cd}+\mathrm{Se}$ (IV) treatment, and Cd + SeMet treatment significantly reduced $\mathrm{Cd}$ content in the roots by $11 \%, 5 \%$, and $16 \%$, respectively, compared with $\mathrm{Cd}$ 
alone treatment (Figure 1A). However, there was no significant difference in root Cd content between $\mathrm{Cd}+\mathrm{Se}(\mathrm{VI})$ treatment and $\mathrm{Cd}$ alone treatment. Cd content in the shoots was significantly reduced by all forms of Se (Figure 1B); Cd + SeMet treatment showed maximum reduction (43\%). Figure 1C shows the transfer factor of $\mathrm{Cd}$ from roots to shoots for rice seedlings supplemented with different forms of Se. The transfer factor of Cd alone treatment (0.18) was significantly more than that of all forms of Se supplements. The transfer factor of Cd + Nano-Se treatment was significantly more than that of the other three Se treatments. The significant changes in transfer factor and shoot Cd content suggest that Se treatment can reduce root-to-shoot $\mathrm{Cd}$ translocation.
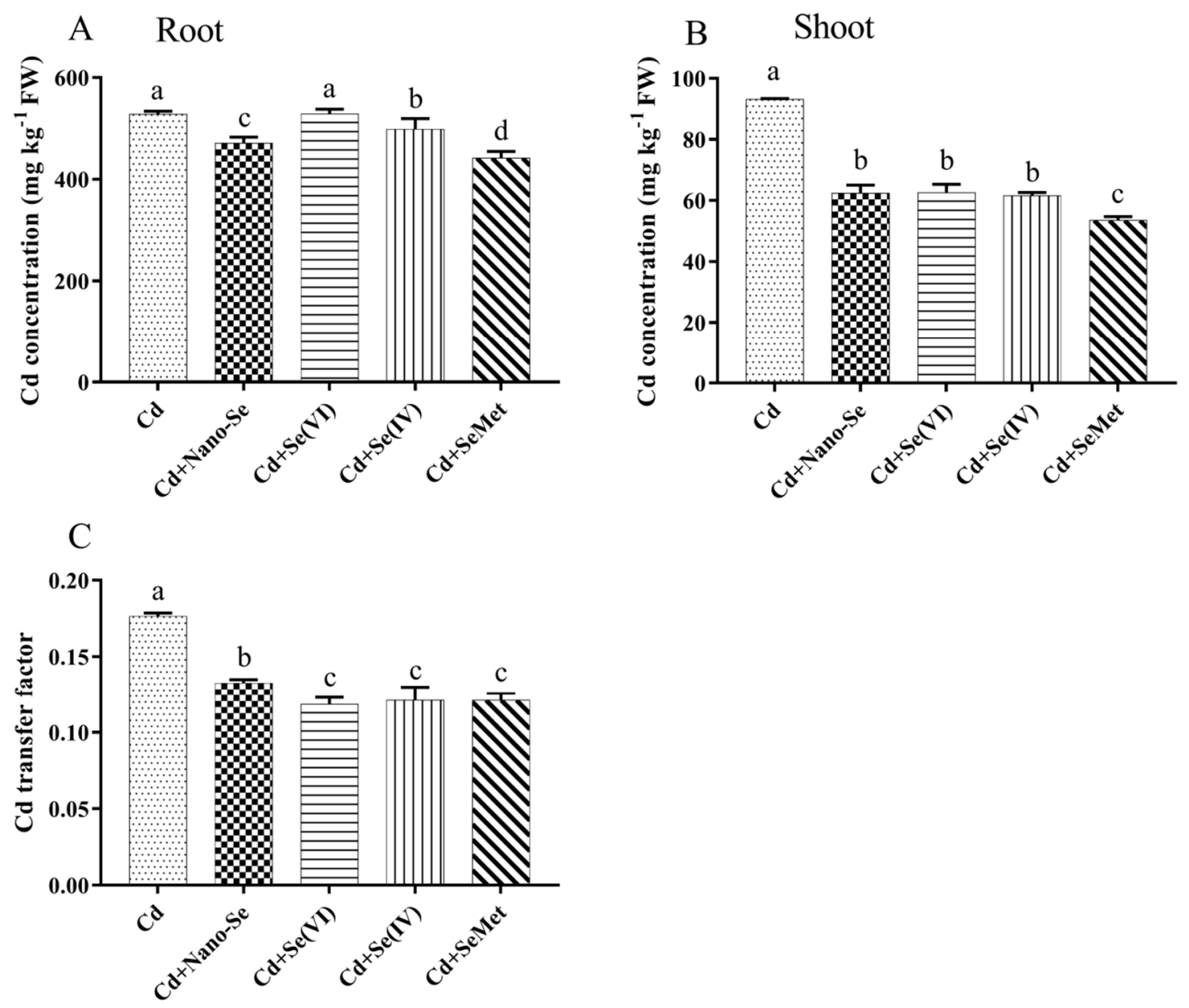

Figure 1. Effects of different Se forms on the Cd concentration in the roots (A) and shoots (B) and $\mathrm{Cd}$ transfer factor $(\mathrm{C})$ in rice seedlings in the presence of $\mathrm{Cd}$. Data points and error bars represent mean values $\pm \mathrm{SD}(n=3)$. The different letters indicate statistically significant differences between the treatments at $p<0.05$.

\subsection{Effects of Se Forms on Subcellular Distribution of Cd in Rice Seedlings under Cd Stress}

Differential centrifugation was used to separate plant cell components into four parts: cell wall, organelles, cell membrane, and soluble fraction. Significant differences were observed in the proportion of $\mathrm{Cd}$ concentration among the different fractions (Figure $2 \mathrm{~A})$. In the roots, $\mathrm{Cd}$ in $\mathrm{Cd}$ alone treatment was mainly associated with the cell wall (50\%) and the soluble fraction (41\%) and a minor part (9\%) was stored in the organelles and the cell membranes. Meanwhile, in Se treatment (any form), most of the $\mathrm{Cd}$ was present in the soluble fraction $(48 \%-58 \%)$. The proportion of $\mathrm{Cd}$ in the soluble fraction increased with Se supplements, of which the proportion in Cd + SeMet treatment was 17\% higher than that in Cd alone treatment. 
A Root

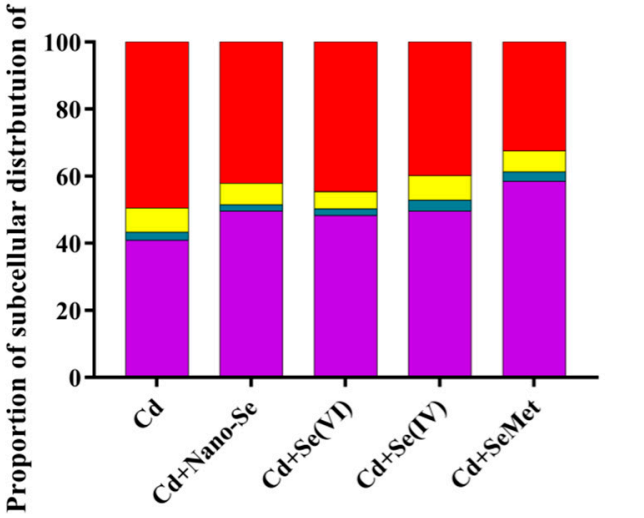

B Shoot

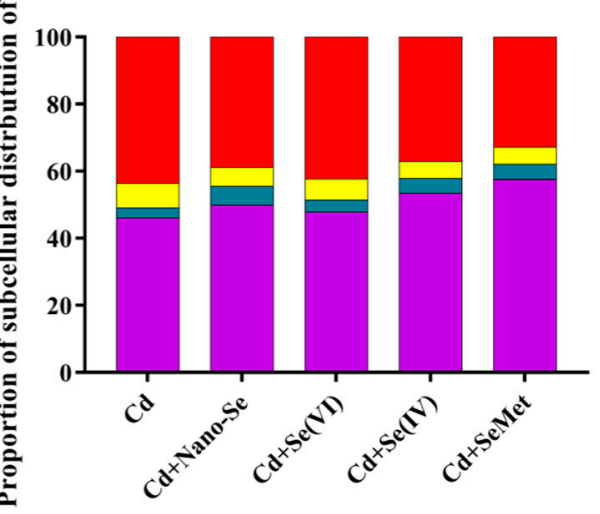

$\square$ cell wall

organelle

soluble fraction

Figure 2. Effects of different Se forms on subcellular distribution of $\mathrm{Cd}$ in the roots (A) and shoots (B) of rice seedlings in the presence of $\mathrm{Cd}$.

The subcellular distribution of $\mathrm{Cd}$ in the shoots showed a trend similar to that in the roots (Figure 2B). The proportion of $\mathrm{Cd}$ in the cell wall was highest in the seedlings treated with $\mathrm{Cd}$ alone, which was significantly higher than that of Cd + Nano-Se treatment, Cd + Se (IV) treatment, and Cd + SeMet treatment. The proportion in the soluble fraction in all forms of Se was also more than that in $\mathrm{Cd}$ alone treatment. However, for roots and shoots, there was no significant $(p>0.05)$ difference in the proportion of $\mathrm{Cd}$ in the organelles and cell membranes between $\mathrm{Cd}$ alone treatment and Se treatments.

\subsection{Effects of Se Forms on the Chemical Forms of $\mathrm{Cd}$ in Rice Seedlings under Cd Stress}

The chemical forms of $\mathrm{Cd}$ in roots are shown in Figure 3A; the forms of $\mathrm{Cd}$ extracted by $2 \% \mathrm{HAc}$ and $1 \mathrm{M} \mathrm{NaCl}$ were dominant in each treatment in the roots $(42.5 \%-54 \%$ of total $\mathrm{Cd})$. Meanwhile, the fraction extracted by $0.6 \mathrm{M} \mathrm{HCl}$ was low. In the $\mathrm{Cd}$ alone treatment, water-soluble $\mathrm{Cd}$ and $\mathrm{Cd}$ extracted by $80 \%$ ethanol accounted for $35.5 \%$ of total Cd in roots. Higher amounts of Cd extracted by $80 \%$ ethanol and water were observed in $\mathrm{Cd}$ alone treatment than that in Se treatments. Whereas $\mathrm{Cd}$ extracted by $0.6 \mathrm{M} \mathrm{HCl}$ in $\mathrm{Cd}+\mathrm{Se}(\mathrm{VI})$ treatment was the highest. In the shoots, the trend was similar to that in the roots (Figure 3B). Cd fractions extracted by $1 \mathrm{M} \mathrm{NaCl}$ and $2 \% \mathrm{HAC}$ were also predominant in the shoots, accounting for $54 \%-60 \%$ of total $\mathrm{Cd}$. However, $\mathrm{Cd}$ extracted by $1 \mathrm{M} \mathrm{NaCl}$, $80 \%$ ethanol, and $0.6 \mathrm{M} \mathrm{HCl}$ were higher in all forms of Se treatments than that in $\mathrm{Cd}$ alone treatment, while $\mathrm{Cd}$ extracted by water was lower than that in $\mathrm{Cd}$ alone treatment.

\subsection{Effects of Se Forms on Se Concentration in Roots and Shoots of Rice Seedlings under Cd Stress}

The concentration of Se in the roots and shoots of rice seedlings under Cd stress was significantly affected by Se supplements (Figure 4). No significant differences were observed in the root and shoot Se between $\mathrm{Cd}$ alone and control. Compared to the $\mathrm{Cd}$ alone treatment, $\mathrm{Cd}+\mathrm{Nano}-\mathrm{Se}, \mathrm{Cd}+\mathrm{Se}(\mathrm{IV})$, $\mathrm{Cd}+\mathrm{Se}(\mathrm{VI})$, and Cd + SeMet treatments significantly increased Se in the roots by $2.8,15.7,1.6$, and 34.0 fold, respectively, and in the shoots by $0.7,5.9,1.0$, and 99.5 fold, respectively. 


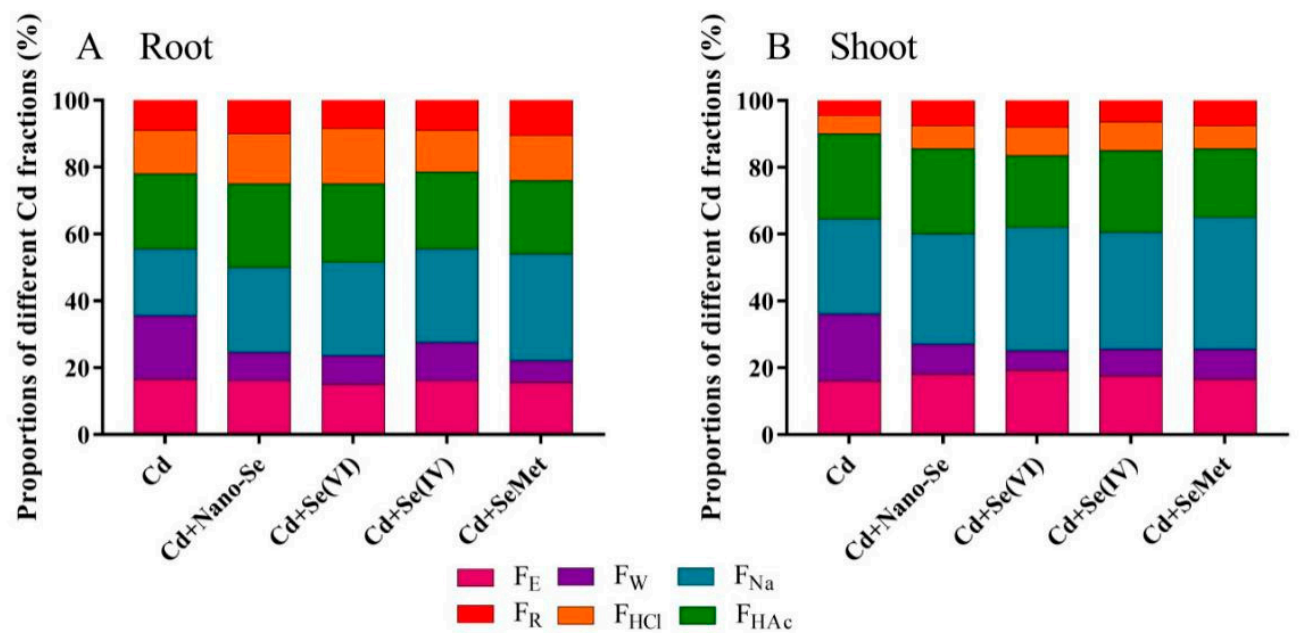

Figure 3. Effects of different Se forms on chemical forms of $\mathrm{Cd}$ in the roots (A) and shoots (B) of rice seedlings in the presence of $\mathrm{Cd}$.
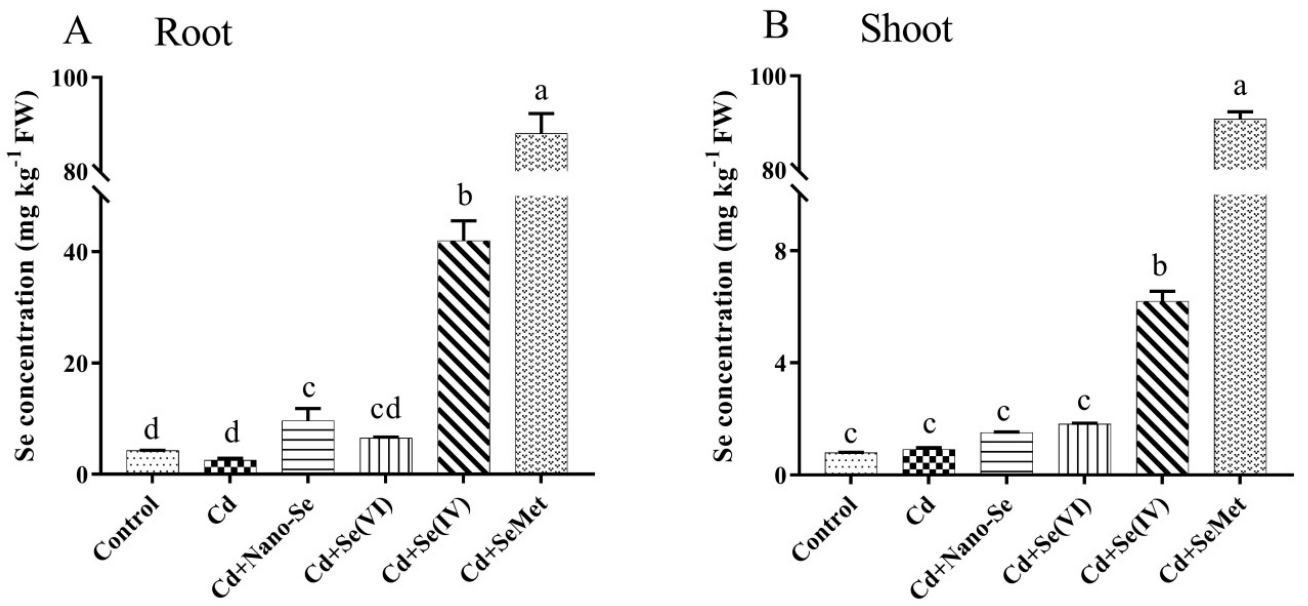

Figure 4. Effects of different Se forms on Se concentration in the roots (A) and shoots (B) of rice seedlings in the presence of $\mathrm{Cd}$. Data points and error bars represent mean values $\pm \mathrm{SD}(n=3)$. The different letters indicate statistically significant differences between the treatments at $p<0.05$.

\subsection{Effects of Se Forms on Antioxidant Enzyme Activities in Rice Seedlings under Cd Stress}

We further investigated the effects of different forms and concentrations of Se on antioxidant enzyme activities in rice seedlings under $\mathrm{Cd}$ stress. In the $\mathrm{Cd}$ alone treatment, MDA content was significantly increased by $372 \%$ compared with that in control (Figure 5A). Moreover, POD and SOD activities increased significantly by $129 \%$ and $107 \%$, respectively, under Cd stress compared with the control (Figure 5B,C), while CAT and GSH-Px activities significantly decreased by $73 \%$ and $32 \%$, respectively (Figure 5D,E). All Se supplements significantly reduced the increase in Cd-mediated MDA content, but did not return to the level of control. The MDA levels of Cd + Nano-Se treatment, $\mathrm{Cd}+$ Se (VI) treatment, Cd + Se (IV) treatment, and Cd + SeMet treatment decreased by $18 \%, 32 \%, 39 \%$, and $52 \%$, respectively, compared with Cd alone treatment. Se addition decreased the POD and SOD activities to different levels, compared with $\mathrm{Cd}$ alone treatment. Among them, POD activities of the leaves treated with Nano-Se, Se (VI), Se (IV), and SeMet significantly decreased by $20 \%, 11 \%, 32 \%$, and $42 \%$, respectively, compared to the $\mathrm{Cd}$ alone treatment. The SOD activities in the leaves were reduced by $32 \%, 29 \%, 42 \%$, and $48 \%$ in Cd + Nano -Se treatment, Cd + Se (VI) treatment, Cd + Se (IV) treatment, and Cd + SeMet treatment, respectively, and the SOD activity in Cd + SeMet treatment was close to that in control. In terms of CAT activity, Se addition, especially Cd + SeMet treatment (increased 
by 2.05-fold compared with the $\mathrm{Cd}$ alone treatment), effectively alleviated $\mathrm{Cd}$-induced reduction in CAT activity. Additionally, CAT activities in Cd + Nano-Se treatment, Cd + Se (VI) treatment, and Cd + Se (IV) treatment were significantly increased by $0.56,1.00$, and 1.45 fold, respectively, compared with the $\mathrm{Cd}$ alone treatment. A similar trend was observed in GSH-Px activity. Se addition significantly increased the GSH-Px activity compared to Cd alone treatment. Additionally, compared to the control treatment, the GSH-Px activities in Cd + Se (IV) treatment and Cd + SeMet treatment were significantly increased by $16 \%$ and $97 \%$, respectively.

A

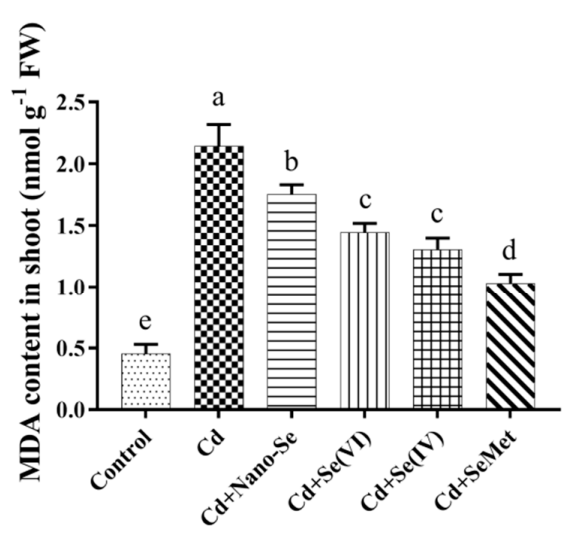

$\mathrm{C}$

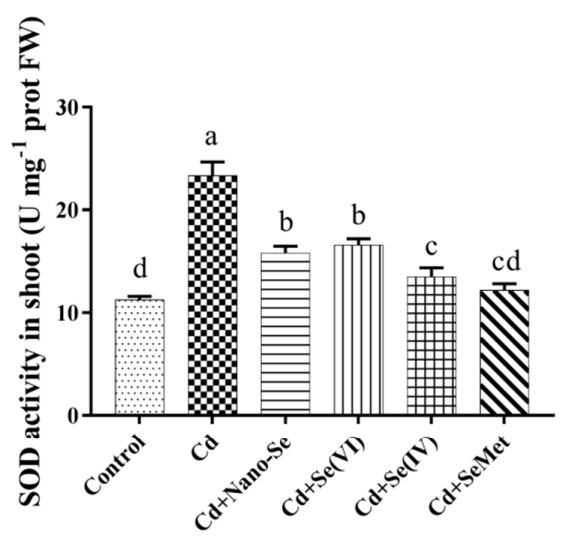

$\mathrm{E}$

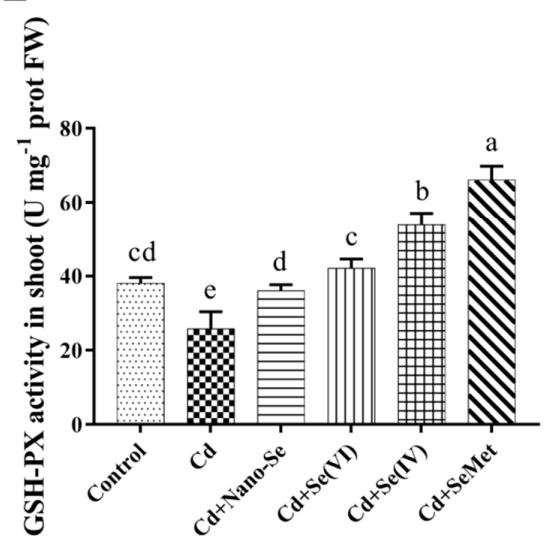

B

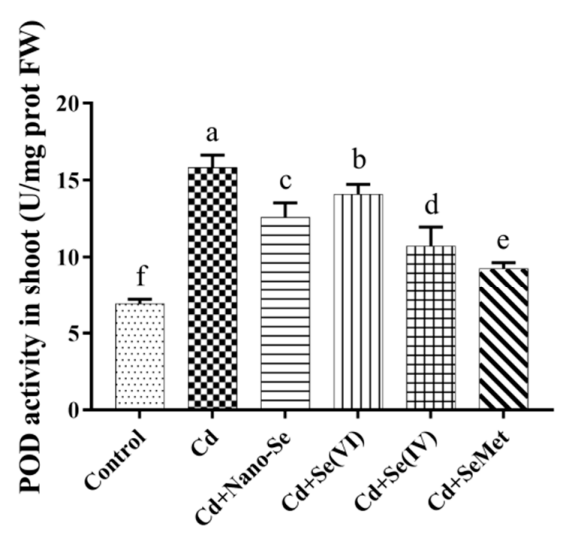

D

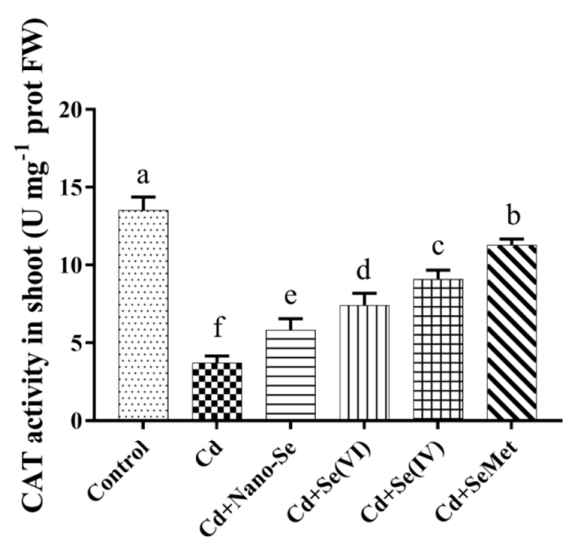

Figure 5. Effects of different Se forms on malondialdehyde (MDA) content (A) and peroxidase (POD) (B), superoxide dismutase (SOD) (C), catalase (CAT) (D), and glutathione peroxidase (GSH-Px) (E) activities of rice seedlings in the presence of $\mathrm{Cd}$. Data points and error bars represent mean values $\pm \operatorname{SD}(n=3)$. The different letters indicate statistically significant differences between the treatments at $p<0.05$. 


\section{Discussion}

Cd contamination in soil has become a global concern. Several studies have demonstrated the harmful effects of $\mathrm{Cd}$ on plant growth, mainly manifested as leaf chlorosis, restricted root development, and decreased biomass [25,26]. In our study, rice seedlings grown in a solution containing $20 \mu \mathrm{M}$ of $\mathrm{Cd}$ alone for 15 days showed stunted growth (Table 1 ). The reduction in biomass accumulation (mainly fresh weight) under $\mathrm{Cd}$ stress may be due to chlorophyll degradation in rice seedlings (Table 1). The observed degradation of chlorophyll in rice seedlings grown under $\mathrm{Cd}$ stress is consistent with the findings of Tang et al. [27]. They found that exposure to Cd stress diminished the chlorophyll content by about $27.5 \%$ compared to control. Cd stress, which affects the structure of chloroplast and chloroplast membrane, promotes ion exchange in the chloroplasts and inhibits the essential enzymes of the Calvin cycle, reduces chlorophyll content, and ultimately inhibits plant growth [28]. Although Se is not an essential element for plants, studies have proven its ability to improve plant growth under heavy metal stress [13,27]. In our study, Se promoted biomass accumulation, and SeMet resulted in a pronounced effect. The positive impact of Se on the growth of rice seedlings under Cd stress may be due to the reversal of Cd-induced chlorophyll degradation (Table 1). Filek et al. [29] confirmed less degradation of chloroplasts in plants cultured in media containing Se under Cd stress. Our findings are consistent with this earlier report. Similarly, Ahmad et al. [11] reported that Se protects plants under stress via enhanced starch accumulation in the chloroplasts.

The heavy metal $\mathrm{Cd}$ is easily transferred from soil to plants under $\mathrm{Cd}$ stress. Studies have reported that the use of inorganic Se decreased Cd uptake in tomato [21], pakchoi [30], wheat [31], and other plants [10,32]. In this study, the addition of Nano-Se, Se (IV), and SeMet significantly reduced the Cd content in rice tissues (shoots and roots), and this effect was pronounced with the SeMet application. Contrarily, a considerable variation in root $\mathrm{Cd}$ content was not found with the addition of Se (VI), while a decline in shoot Cd content was observed (Figure 1). Similarly, Yu et al. [30] reported that Se (IV) reduced Cd content in the shoots of pakchoi, while Se (VI) increased. Alves et al. [21] reported that both Se (IV) and Se (VI) reduced Cd uptake in tomato (Solanum lycopersicum L.). These results suggest that the specific effect depends on Cd dosage and plant species as well as Se species. Moreover, all species of Se reduced the transfer factor of $\mathrm{Cd}$ in rice seedlings (Figure 1). Rice roots act as a barrier against $\mathrm{Cd}$ translocation, while the beneficial effect of Se was significantly related to the reduction in Cd uptake or translocation towards the shoots.

In roots, the accumulation and proportion of $\mathrm{Cd}$ in the different subcellular fractions were as follows: cell wall $(50 \%)>$ cytosol $(41 \%)>$ organelles $(9 \%)$ (Figure 2). This pattern could be related to the specific mechanisms employed by the plant to alleviate Cd stress. In plants, the cell wall is the first barrier, which prevents $\mathrm{Cd}$ ions from entering into the plant [33]. Due to the limited ability of the cell wall to fix $\mathrm{Cd}$ at high concentrations, the soluble fraction merges $\mathrm{Cd}$ with thiol (-SH) groups (e.g., GSH and phytochelatins [PCs]) to form complexes, which induce less cell organelle damage [34]. Schmöger et al. [34] observed that sulfur can promote vacuole compartmentalization of Cd. Similar mechanism with Se. Exogenous Se could significantly reduce the proportion of $\mathrm{Cd}$ in the cell wall and subsequently increase the proportion of $\mathrm{Cd}$ in the soluble fraction (Figure 2); this finding is consistent with the reports of $\mathrm{Yu}$ et al. [30]. These results suggest that Se can promote vacuole and cell wall sequestration of $\mathrm{Cd}$ in the roots. Se, which is chemically similar to sulfur, may also contribute to $\mathrm{Cd}$ sequestration by stimulating the production of GSH and PCs in plants [35]. Moreover, in plants, Cd is absorbed by the roots and subsequently transferred to the shoots. The forms of $\mathrm{Cd}$ that already exist in plants can directly affect the migration ability and activity, and Cd fractions extracted by $80 \%$ ethanol and water are the most active [23]. In this study, the proportions of $\mathrm{Cd}$ extracted by $2 \% \mathrm{HAc}$ and $1 \mathrm{M} \mathrm{NaCl}$ were dominant in the plant, similar to the results of Wang et al. [36]. The addition of Se markedly reduced the proportions of Cd extracted by $80 \%$ ethanol and water in the roots (Figure 3). These results indicate that Se reduces $\mathrm{Cd}$ accumulation in shoots by inhibiting root-to-shoot $\mathrm{Cd}$ translocation. To conclude, Se increases sequestration of $\mathrm{Cd}$ in cell walls and vacuoles and decreases the active chemical form of $\mathrm{Cd}$ in rice seedlings, thereby reducing $\mathrm{Cd}$ accumulation in the shoots 
Differences in the effects of Se species on the concentration and distribution of $\mathrm{Cd}$ in rice seedlings were probably due to the differences in their absorption and assimilation (Figure 4). Rice plants preferentially take up and accumulate organic forms of Se compared to inorganic forms $[15,32,37,38]$. Moreover, organic Se is easier to transport to the shoot [39]. Previous studies have found that Nano-Se is absorbed by plant roots through physical or chemical pathways, and small Nano-Se forms easily pass through the cell wall barrier and get absorbed by the plant roots [40], therefore cell wall is the primary limiting factor for Nano-Se absorption. In summary, the study reveals a better effect of SeMet due to improved plant absorption and utilization.

Heavy metals exert toxic effects on plants through the generation of free radicals, such as superoxide radical $\left(\mathrm{O}^{2-}\right)$, hydrogen peroxide $\left(\mathrm{H}_{2} \mathrm{O}_{2}\right)$, and hydroxyl radical $(\mathrm{OH})$, called reactive oxygen species (ROS). ROS initiate the peroxidation and destruction of the lipid bilayer that lead to irreparable metabolic dysfunction and cell death [21]. In our study, $\mathrm{Cd}$ increased the MDA level in rice roots (Figure 5), probably due to increase lipid peroxidation caused by $\mathrm{Cd}$-induced oxidative stress. Similar findings have been reported in rape and wheat seedlings [41]. Under such stressful situations, plants develop an antioxidant defense system, which plays a vital role in alleviating oxidative stress. In the current study, the activities of CAT and GSH-Px considerably reduced while that of SOD and POD significantly increased under $\mathrm{Cd}$ stress (Figure 5). Antioxidant enzymes exhibit dual behavior under Cd stress depending on Cd dose and plant species. Tang et al. [42] reported POD and SOD activities of rice seedlings were significantly increased under Cd stress. Maksymiec et al. [43] found that $\mathrm{Cd}$ at high concentrations increased free radical production, enhanced SOD activity, and decreased CAT activity in Arabidopsis thaliana. The decline in CAT and GSH-Px activities in plants under Cd stress suggests the decrease in antioxidant efficiency. However, the decrease in MDA level is due to the reduction of $\mathrm{Cd}$-induced oxidative stress by exogenous Se. A sharp increase in CAT and GSH-Px activities and a decrease in SOD and POD activities in shoots as compared to $\mathrm{Cd}$ alone treated seedlings were observed in this study (Figure 5). Thus, Se helps rice seedlings to adapt to Cd stress. Similarly, Se regulated antioxidant enzyme activities (e.g., CAT, GSH-Px, SOD, and POD) in plants under heavy metal stress [26,27]. In our study, the effect of Se in alleviating Cd stress was dependent on the Se species. SeMet application was the most effective in regulating the antioxidant enzyme activities.

\section{Conclusions}

To conclude, this study reveals that the effects of Se on the physiological response and Cd uptake of rice seedlings depend on the form of Se applied. All forms of Se, except Se (VI), significantly enhanced biomass accumulation and chlorophyll content. Besides, Se application affected Cd accumulation in rice seedlings by altering $\mathrm{Cd}$ subcellular distribution (in cell walls and vacuoles) and forms of $2 \%$ HAc and $1 \mathrm{M} \mathrm{NaCl}$ extracted $\mathrm{Cd}$ with low mobility, and by enhancing antioxidative defense. However, such effects depend on the Se form applied. Among the different forms of Se used in this study, SeMet resulted in a pronounced effect in alleviating Cd stress in rice seedlings.

Author Contributions: H.X.: Conceptualization, Methodology, Formal analysis, Manuscript Writing. J.Y.: Formal analysis, Visualization, Investigation. Y.Q.: Formal analysis. J.X.: Formal analysis. M.J.I.S.: Formal analysis, Manuscript review. Y.W.: Conceptualization, Supervision, Funding acquisition. M.G.: Supervision, Funding acquisition. All authors have read and agreed to the published version of the manuscript.

Funding: This research was financially supported by the Innovation Driven Special Foundation of Guangxi (Guike AA17202038), and the Provincial Natural Science Foundation of Guangxi (2015GXNSFBA139047).

Conflicts of Interest: The authors declare no competing financial interests or personal relationships that could have appeared to influence the work reported in this paper. 


\section{References}

1. Zhao, F.J.; Wang, P. Arsenic and cadmium accumulation in rice and mitigation strategies. Plant Soil 2020, 446, 1-21. [CrossRef]

2. Demim, S.; Drouiche, N.; Aouabed, A.; Benayad, T.; Dendene-Badache, O.; Semsari, S. Cadmium and nickel: Assessment of the physiological effects and heavy metal removal using a response surface approach by $L$. gibba. Ecol. Eng. 2013, 61, 426-435. [CrossRef]

3. Liu, W.; Shang, S.; Feng, X.; Zhang, G.; Wu, F. Modulation of exogenous selenium in cadmium-induced changes in antioxidative metabolism, cadmium uptake, and photosynthetic performance in the 2 tobacco genotypes differing in cadmium tolerance. Environ. Toxicol. Chem. 2015, 34, 92-99. [CrossRef]

4. Saidi, I.; Chtourou, Y.; Djebali, W. Selenium alleviates cadmium toxicity by preventing oxidative stress in sunflower (Helianthus annuus) seedlings. J. Plant. Physiol. 2014, 171, 85-91. [CrossRef] [PubMed]

5. Pedrero, Z.; Madrid, Y.; Hartikainen, H.; Cámara, C. Protective Effect of selenium in broccoli (Brassica oleracea) plants subjected to cadmium exposure. J. Agric. Food. Chem. 2008, 56, 266-271. [CrossRef] [PubMed]

6. Chen, J.; Huang, X.Y.; Salt, D.E.; Zhao, F. Mutation in OsCADT1 enhances cadmium tolerance and enriches selenium in rice grain. New Phytol. 2020, 226, 838-850. [CrossRef] [PubMed]

7. Zhu, P.; Liang, X.; Wang, P.; Wang, J.; Gao, Y.; Hu, S.; Huang, Q.; Huang, R.; Jiang, Q.; Wu, S.; et al. Assessment of dietary cadmium exposure: A cross-sectional study in rural areas of south China. Food Control 2016, 62, 284-290. [CrossRef]

8. Hu, Y.; Cheng, H.; Tao, S. The Challenges and solutions for cadmium-contaminated rice in China: A critical review. Environ. Int. 2016, 92-93, 515-532. [CrossRef]

9. Wan, Y.; Yu, Y.; Wang, Q.; Qiao, Y.; Li, H. Cadmium uptake dynamics and translocation in rice seedling: Influence of different forms of selenium. Ecotoxicol. Environ. Saf. 2016, 133, 127-134. [CrossRef]

10. Shanker, K.; Mishra, S.; Srivastava, S.; Srivastava, R.; Dass, S.; Prakash, S.; Srivastava, M.M. Effect of selenite and selenate on plant uptake of cadmium by kidney bean (Phaseolus mungo) with reference to Cd-Se interaction. Chem. Spec. Bioavailab. 2015, 7, 97-100. [CrossRef]

11. Ahmad, P.; Abd Allah, E.F.; Hashem, A.; Sarwat, M.; Gucel, S. Exogenous application of selenium Mitigates Cadmium Toxicity in Brassica juncea L. (Czern \& Cross) by up-regulating antioxidative system and secondary metabolites. J. Plant Growth Regul. 2016, 35, 936-950.

12. Lin, L.; Zhou, W.; Dai, H.; Cao, F.; Zhang, G.; Wu, F. Selenium reduces cadmium uptake and mitigates cadmium toxicity in rice. J. Hazard. Mater. 2012, 235-236, 343-351. [CrossRef] [PubMed]

13. Feng, R.; Wei, C.; Tu, S. The roles of selenium in protecting plants against abiotic stresses. Environ. Exp. Bot. 2013, 87, 58-68. [CrossRef]

14. Mozafariyan, M.; Shekari, L.; Hawrylak-Nowak, B.; Kamelmanesh, M.M. Protective role of selenium on pepper exposed to cadmium stress during reproductive stage. Biol. Trace Elem. Res. 2014, 160, 97-107. [CrossRef]

15. Kikkert, J.; Berkelaar, E. Plant uptake and translocation of inorganic and organic forms of selenium. Arch. Environ. Con. Tox. 2013, 65, 458-465. [CrossRef]

16. Schiavon, M.; Pilon-Smits, E.A. The fascinating facets of plant selenium accumulation-Biochemistry, physiology, evolution and ecology. New Phytol. 2017, 213, 1582-1596. [CrossRef]

17. El-Ramady, H.R.; Domokos-Szabolcsy, É.; Abdalla, N.A.; Alshaal, T.A.; Shalaby, T.A.; Sztrik, A.; Prokisch, A.; Fári, M. Selenium and nano-selenium in agroecosystems. Environ. Chem. Lett. 2014, 12, 495-510. [CrossRef]

18. Li, Y.; Zhu, N.; Liang, X.; Zheng, L.; Zhang, C.; Li, Y.; Zhang, Z.; Gao, Y.; Zhao, J. A comparative study on the accumulation, translocation and transformation of selenite, selenate, and SeNPs in a hydroponic-plant system. Ecotoxicol. Environ. Saf. 2020, 189, 109955. [CrossRef]

19. Hu, T.; Li, H.; Li, J.; Zhao, G.; Wu, W.; Liu, L.; Wang, Q.; Guo, Y. Absorption and bio-transformation of selenium nanoparticles by wheat seedlings (Triticum aestivum L.). Front. Plant Sci. 2018, 9, 597. [CrossRef]

20. Wu, Y.J.; Ni, Y.H. Experiment in the Nano-selenium-added in cabbage. J. Anhui Agri. Sci. 2011, 39, 18440-18442. 
21. Alves, L.R.; Rodrigues dos Reis, A.; Prado, E.R.; Lavres, J.; Pompeu, G.B.; Azevedo, R.A.; Gratão, P.L. New insights into cadmium stressful-conditions: Role of ethylene on selenium-mediated antioxidant enzymes. Ecotoxicol. Environ. Saf. 2019, 186, 109747. [CrossRef] [PubMed]

22. Weigel, H.J.; Jäger, H.J. Subcellular distribution and chemical form of cadmium in bean plants. J. Plant Physiol. 1980, 65, 480-482. [CrossRef] [PubMed]

23. Wu, F.B.; Dong, J.; Qian, Q.Q.; Zhang, G.P. Subcellular distribution and chemical form of Cd and Cd-Zn interaction in different barley genotypes. Chemosphere 2005, 60, 1437-1446. [CrossRef] [PubMed]

24. Li, H.X.; Xiao, Y.; Cao, L.L.; Yan, X.; Li, C.; Shi, H.Y.; Wang, J.W.; Ye, Y.H. Cerebroside C increases tolerance to chilling injury and alters lipid composition in wheat roots. PLOS ONE 2013, 8, e73380. [CrossRef]

25. Ahsan, N.; Lee, S.H.; Lee, D.G.; Lee, H.; Lee, S.W.; Bahk, J.D.; Lee, B.H. Physiological and protein profiles alternation of germinating rice seedlings exposed to acute cadmium toxicity. C. R. Biol. 2007, 330, 735-746. [CrossRef] [PubMed]

26. Huang, G.; Ding, C.; Guo, F.; Li, X.; Zhang, T.; Wang, X. Underlying mechanisms and effects of hydrated lime and selenium application on cadmium uptake by rice (Oryza sativa L.) seedlings. Environ. Sci. Pollut. Res. 2017, 24, 18926-18935. [CrossRef]

27. Tang, H.; Liu, Y.; Gong, X.; Zeng, G.; Zheng, B.; Wang, D.; Sun, Z.; Zhou, L.; Zeng, X. Effects of selenium and silicon on enhancing antioxidative capacity in ramie (Boehmeria nivea (L.) Gaud.) under cadmium stress. Environ. Sci. Pollut. Res. Int. 2015, 22, 9999-10008. [CrossRef] [PubMed]

28. Alyemeni, M.N.; Ahanger, M.A.; Wijaya, L.; Alam, P.; Bhardwaj, R.; Ahmad, P. Selenium mitigates cadmium-induced oxidative stress in tomato (Solanum lycopersicum L.) plants by modulating chlorophyll fluorescence, osmolyte accumulation, and antioxidant system. Protoplasma 2018, 255, 459-469. [CrossRef] [PubMed]

29. Filek, M.; Koscielniak, J.; Labanowska, M.; Bednarska, E.; Bidzinska, E. Selenium-induced protection of photosynthesis activity in rape (Brassica napus) seedlings subjected to cadmium stress. Fluorescence and EPR measurements. Photosynth. Res. 2010, 105, 27-37. [CrossRef]

30. Yu, Y.; Fu, P.; Huang, Q.; Zhang, J.; Li, H. Accumulation, subcellular distribution, and oxidative stress of cadmium in Brassica chinensis supplied with selenite and selenate at different growth stages. Chemosphere 2019, 216, 331-340. [CrossRef]

31. Qin, X.; Nie, Z.; Liu, H.; Zhao, P.; Qin, S.; Shi, Z. Influence of selenium on root morphology and photosynthetic characteristics of winter wheat under cadmium stress. Environ. Exp. Bot. 2018, 150, 232-239. [CrossRef]

32. Yin, H.; Qi, Z.; Li, M.; Ahammed, G.J.; Chu, X.; Zhou, J. Selenium forms and methods of application differentially modulate plant growth, photosynthesis, stress tolerance, selenium content and speciation in Oryza sativa L. Ecotoxicol. Environ. Saf. 2019, 169, 911-917. [CrossRef]

33. Fan, J.L.; Wei, X.Z.; Wan, L.C.; Zhang, L.Y.; Zhao, X.Q.; Liu, W.Z.; Hao, H.Q.; Zhang, H.Y. Disarrangement of actin filaments and $\mathrm{Ca}^{2+}$ gradient by $\mathrm{CdCl}_{2}$ alters cell wall construction in Arabidopsis thaliana root hairs by inhibiting vesicular trafficking. J. Plant Physiol. 2011, 168, 1157-1167. [CrossRef]

34. Schmöger, M.E.V.; Oven, M.; Grill, E. Detoxification of arsenic by phytochelatins in plants. Plant Physiol. 2000, 122, 793-802.

35. Gupta, M.; Gupta, S. An Overview of selenium uptake, metabolism, and toxicity in plants. Front. Plant Sci. 2017, 7, 2074. [CrossRef] [PubMed]

36. Wang, X.; Liu, Y.; Zeng, G.; Chai, L.; Song, X.; Min, Z.; Xiao, X. Subcellular distribution and chemical forms of cadmium in Bechmeria nivea (L.) Gaud. Environ. Exp. Bot. 2008, 62, 389-395. [CrossRef]

37. Pyrzynska, K. Selenium speciation in enriched vegetables. Food Chem. 2009, 114, 1183-1191. [CrossRef]

38. Zayed, A.; Terry, L.N. Accumulation and volatilization of different chemical species of selenium by plants. Planta 1998, 206, 284-292. [CrossRef]

39. Zhang, L.H.; Shi, W.M.; Wang, X.C. Difference in selenium accumulation in shoots of two rice cultivars. Pedosphere 2006, 16, 646-653. [CrossRef]

40. Aslani, F.; Bagheri, S.; Muhd Julkapli, N.; Juraimi, A.S.; Hashemi, F.S.; Baghdadi, A. Effects of engineered nanomaterials on plants growth: An overview. Sci. World J. 2014, 2014, 641759. [CrossRef]

41. Zembala, M.; Filek, M.; Walas, S.; Mrowiec, H.; Kornaś, A.; Miszalski, Z.; Hartikainen, H. Effect of selenium on macro- and microelement distribution and physiological parameters of rape and wheat seedlings exposed to cadmium stress. Plant Soil 2009, 329, 457-468. [CrossRef] 
42. Tang, Q.; Zhang, S.; Li, H.X.; Zhang, C.B.; Liu, Z.Q. Alleviation of calcium on toxicity of cadmium to rice seedlings by inhibiting cadmium accumulation and relieving oxidative damage. J. Northeast Agric. Univ. 2019, 26, 33-40.

43. Maksymiec, W.; Krupa, Z. The effects of short-term exposition to Cd, excess Cu ions and jasmonate on oxidative stress appearing in Arabidopsis thaliana. Environ. Exp. Bot. 2006, 57, 187-194. [CrossRef] 